
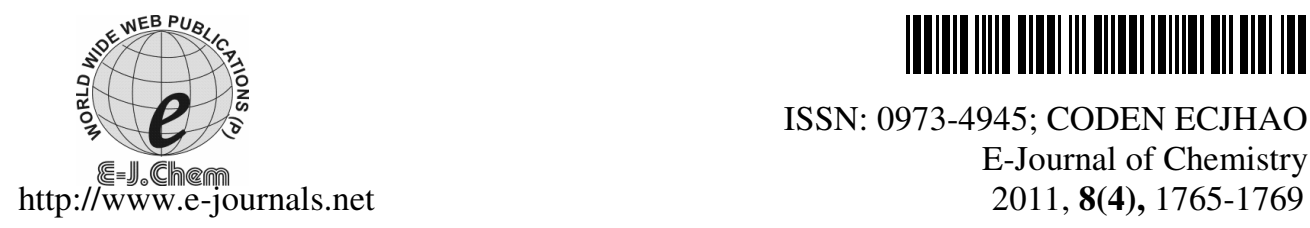

ISSN: 0973-4945; CODEN ECJHAO

E-Journal of Chemistry 2011, 8(4), 1765-1769

\title{
Stability Constants of Mixed Ligand Complexes of Transition Metal(II) Ions with Salicylidene-4-methoxyaniline as Primary Ligand and 5-Bromosalicylidene-4- nitroaniline as Secondary Ligand
}

\author{
N. G. NADKARNI* and K. V. MANGAONKAR \\ *Pathkar College Goregaon (W) \\ Mumbai: - 4000, Maharashtra, India \\ Mithibai College, Vile-Parle (W) \\ Mumbai: - 400056, Maharashtra, India \\ nadkarni@gmail.com
}

Received 21 November 2010; Revised 27 February 2011; Accepted 28 February 2011

\begin{abstract}
Binary and ternary complexes of the type M-Y and M-X-Y $[\mathrm{M}=\mathrm{Mn}(\mathrm{II}), \mathrm{Ni}(\mathrm{II}), \mathrm{Cu}(\mathrm{II})$ and $\mathrm{Zn}(\mathrm{II}) ; \mathrm{X}=$ salicylidene-4-methoxyaniline and $\mathrm{Y}=5$-bromosalicylidene-4-nitroaniline] have been examined $\mathrm{pH}$-metrically at $27 \pm 0.5{ }^{\circ} \mathrm{C}$ and at constant ionic strength, $\mu=0.1 \mathrm{M}(\mathrm{KCl})$ in $75: 25(\mathrm{v} / \mathrm{v}) 1,4$-dioxne-water medium. The stability constants for binary $(\mathrm{M}-\mathrm{Y})$ and ternary $(\mathrm{M}-\mathrm{X}-\mathrm{Y})$ systems were calculated. The relative stability $\left(\Delta \log \mathrm{K}_{\mathrm{T}}\right)$ values of the ternary complexes with corresponding binary complexes for all the metal(II) ions in the present study found to be negative indicating that ternary $1: 1: 1(\mathrm{M}-\mathrm{X}-\mathrm{Y})$ complexes are less stable than binary 1:1 (M-Y) complexes. In the ternary system studied, the order of stability constants of mixed ligand complexes with respect to the metal ions was found to be $\mathrm{Cu}(\mathrm{II})>\mathrm{NI}(\mathrm{II})>\mathrm{Mn}(\mathrm{II})>\mathrm{Zn}$ (II); which is same as in the corresponding binary (M-Y) systems.
\end{abstract}

Keywords: Binary complexes, Ternary complexes, Mixed ligand, Stability constant

\section{Introduction}

Metal complexes of the Schiff bases have occupied a central role in the development of coordination chemistry ${ }^{1}$. Many attempts have been made to evaluate different factors affecting the stability of the metal chelates along with their stability constants $\mathrm{s}^{2-4}$. In the present 
study the stability constants of the mixed ligand complexes of $\mathrm{Mn}(\mathrm{II}), \mathrm{Ni}(\mathrm{II}), \mathrm{Cu}(\mathrm{II})$ and $\mathrm{Zn}$ (II) with salicylidene-4-methoxyaniline (X) as primary ligand and 5-bromosalicylidene4-nitroaniline $(\mathrm{Y})$ as secondary ligand in 75: 25(v/v) 1,4-dioxane-water medium at $27 \pm 0.5{ }^{\circ} \mathrm{C}$ have been reported by employing $\mathrm{pH}$-metric titration technique $\mathrm{e}^{5-10}$. Under identical conditions the stability constants of binary metal complexes of 5-bromosalicylidene-4nitroaniline (Y) have also been investigated.

\section{Experimental}

The $\mathrm{pH}$-meter model no. EQ-614 supplied by Equiptronics, a precision research $\mathrm{pH}$-meter with wide range of glass electrode and calomel reference electrode was used for $\mathrm{pH}$ measurements. The $\mathrm{pH}$-meter was standardized with potassium hydrogen phthalate and phosphate buffers before performing the titrations.

The solutions of ligands were prepared in 1,4-dioxane. All the metal ion solutions were prepared in double distilled water and standardized by using conventional procedures ${ }^{11}$. A solution of $\mathrm{KOH}(0.2 \mathrm{M})$ was prepared in double distilled water and standardized with standard solution of succinic acid. The titrations were carried out in an inert atmosphere of nitrogen. All the measurements were carried out at temperature $27 \pm 0.5{ }^{\circ} \mathrm{C}$. The method of Bjerrum and Calvin as modified by Irving and Rossotti ${ }^{5,6}$ was used to determine $\bar{n}_{\mathrm{A}}$ (average number of protons associated with secondary ligand); $\bar{n}$ (average number of secondary ligand molecules attached per metal ion; $\bar{n}_{\text {mix }}$ (average number of secondary ligand molecules attached per (M.X) ${ }^{-}$ion); pL (free ligand exponent for binary (M-Y) system) and $\mathrm{pL}_{\text {mix }}$ (free ligand exponent for ternary $(\mathrm{M}-\mathrm{X}-\mathrm{Y})$ system) values. All the solvents and chemicals used were of A R grade.

For the determination of proton-ligand stability constant of secondary ligand (Y) and metal-ligand stability constants of binary (M-Y) and ternary (M-X-Y) complexes, the following sets of solutions were prepared keeping the total volume $\mathrm{V}_{\mathrm{o}}=40 \mathrm{~mL}$. All titrations were carried out at the ionic strength of $0.1 \mathrm{M}$ using $\mathrm{KCl}$ as an electrolyte in $75: 25(\mathrm{v} / \mathrm{v})$ 1,4-dioxane-water medium against standard carbonate free $\mathrm{KOH}(0.2 \mathrm{M})$ solution.

i. $\quad 4.0 \mathrm{~mL} \mathrm{HCl}(0.16 \mathrm{M})+3.36 \mathrm{~mL} \mathrm{KCl}(1.0 \mathrm{M})+2.64 \mathrm{~mL}$ distilled water $+30.0 \mathrm{~mL}$ 1,4-dioxane.

ii. $\quad 4.0 \mathrm{~mL} \mathrm{HCl}(0.16 \mathrm{M})+3.36 \mathrm{~mL} \mathrm{KCl}(1.0 \mathrm{M})+2.64 \mathrm{~mL}$ distilled water $+4.0 \mathrm{~mL}$ secondary ligand $(0.04 \mathrm{M})+26.0 \mathrm{~mL} \mathrm{1,4-dioxane.}$

iii. $4.0 \mathrm{~mL} \mathrm{HCl}(0.16 \mathrm{M})+3.24 \mathrm{~mL} \mathrm{KCl}(1.0 \mathrm{M})+$ requisite volume of metal(II) chloride solution to give $0.001 \mathrm{M}$ metal(II) chloride concentration in the final solution + requisite amount of distilled water $+4.0 \mathrm{~mL}$ secondary ligand $(0.04 \mathrm{M})+26.0 \mathrm{~mL}$ 1,4-dioxane.

iv. $4.0 \mathrm{~mL} \mathrm{HCl}(0.16 \mathrm{M})+3.36 \mathrm{~mL} \mathrm{KCl}(1.0 \mathrm{M})+2.64 \mathrm{~mL}$ distilled water $+4.0 \mathrm{~mL}$ secondary ligand $(0.01 \mathrm{M})+26.0 \mathrm{~mL}$ 1,4-dioxane.

v. $\quad 4.0 \mathrm{~mL} \mathrm{HCl}(0.16 \mathrm{M})+3.24 \mathrm{~mL} \mathrm{KCl}(1.0 \mathrm{M})+$ requisite volume of metal(II) chloride solution to give $0.001 \mathrm{M}$ metal(II) chloride concentration in the final solution + requisite amount of distilled water $+4.0 \mathrm{~mL}$ primary ligand $(0.01 \mathrm{M})+4.0 \mathrm{~mL}$ secondary ligand $(0.01 \mathrm{M})+22.0 \mathrm{~mL}$ 1,4-dioxane.

The ratio of metal $(\mathrm{M})$ : secondary ligand $(\mathrm{Y})$ was maintained at 1:4 in the binary system. In the ternary system the ratio of metal $(\mathrm{M})$ : primary ligand $(\mathrm{X})$ : secondary ligand (Y) was maintained at 1:1:1. The $\mathrm{pH}$-meter readings were plotted against the volume of alkali $(\mathrm{KOH})$ used for each titrations. 


\section{Results and Discussion}

\section{Proton-ligand stability constant of secondary ligand $(Y)$}

From the titration curves of solutions (i) and (ii), $\bar{n}_{\mathrm{A}}$ values at various $\mathrm{pH}$ were calculated. The proton ligand formation curve was obtained by plotting the values of $\bar{n}_{\mathrm{A}} v s$. pH-meter readings. From the graph the values of $\log K_{1}^{H}$ and $\log K_{2}^{H}$ were evaluated by half integral method (A). The values of $\log K_{1}^{H}$ and $\log K_{2}^{H}$ were also evaluated using graphical method (B) by plotting the graph of $\log \left[\bar{n}_{\mathrm{A}} /\left(1-\bar{n}_{\mathrm{A}}\right)\right]$ against $\mathrm{pH}$ and $\log \left[\left(2-\bar{n}_{\mathrm{A}}\right) /\left(\bar{n}_{\mathrm{A}}-1\right)\right]$ against $\mathrm{pH}$, respectively. The values obtained by method $\mathrm{A}$ and $\mathrm{B}$ are in agreement with each other, the average values of $\log K_{1}^{H}$ and $\log K_{2}^{H}$ has been found to be 8.40 and 2.80 respectively.

\section{Metal-ligand stability constants of the Binary $(M-Y)$ complexes}

The metal ligand stability constants of binary complexes were evaluated assuming the polynuclear complexes and hydrolyzed products were not formed. An examination of titration curves indicate that complex formation takes place in the solution on the following grounds: (I) The metal titration curve of solution (iii) shows displacement with respect ligand (Y) titration curve of solution (ii) along the volume axis. This indicates the affinity of the ligand to metal ions which release proton and produce volume difference. (II) The color change of ligand appeared in the presence of metal ion shows the formation of new species due to coordination. (III) The hydrolysis of the metal ion was suppressed due to the complex formation and precipitation did not appear during the titrations.

From the titration curves of solutions (ii) and (iii), $\bar{n}$ and $\mathrm{pL}$ values were calculated. The formation curves were obtained by plotting the values of $\bar{n} v s$. pL. From the graph the values of $\log K_{M Y_{1}}^{M}$ and $\log K_{M Y_{2}}^{M Y}$ were evaluated by half integral method (A) and in the similar way the values of $\log K_{M Y_{1}}^{M}$ and $\log K_{M Y_{2}}^{M Y}$ were evaluated using graphical method (B) by plotting the graph of $\log [\bar{n} /(1-\bar{n})]$ against $\mathrm{pL}$ and $\log [(2-\bar{n}) /(\bar{n}-1)]$ against $\mathrm{pL}$ respectively. The values obtained by method $\mathrm{A}$ and $\mathrm{B}$ are in agreement with each other, the average values of $\log K_{M Y_{1}}^{M}$ and $\log K_{M Y_{2}}^{M Y}$, along with metal-ligand stability constants the $\log \beta$ values of the binary complexes are given in Table 1 .

The variations of $\tilde{n}$ was found to be between $0.0-2.0$ for the binary (M-Y) complexes of $\mathrm{Mn}(\mathrm{II}), \mathrm{Ni}(\mathrm{II}), \mathrm{Cu}(\mathrm{II})$ and $\mathrm{Zn}$ (II) metal ions, which indicate that the composition of the complexes were $1: 2$ in solution. The $\log K_{M Y_{1}}^{M}$ values for the binary complexes of the metal ions are in the following order: $\mathrm{Cu}(\mathrm{II})>\mathrm{Ni}$ (II) $>\mathrm{Mn}$ (II) $>\mathrm{Zn}$ (II).

\section{Metal-ligand stability constants of the ternary $(M-X-Y)$ complexes}

The metal-ligand stability constants of ternary complexes were evaluated assuming that the formation of polynuclear complexes and hydrolyzed products were not formed. An examination of the titration curves indicate that the ternary complexes formation has taken place in the solution on the following grounds: The horizontal distance was measured between ternary titration curves of solution (v) and secondary ligand titration curve of solution (iv), the positive difference shows the earlier release of protons in the formation of ternary complexes (II). The hydrolysis of the metal ion was suppressed and precipitation did not appear during the titrations. 
From the titration curves of solutions (iv) and (v), $\bar{n}_{\text {mix }}$ and $\mathrm{pL}_{\text {mix }}$ values were calculated. The values of $\log K_{M X Y}^{M X}$ have been evaluated from the formation curves $\left(\bar{n}_{\text {mix }} v s\right.$. $\left.\mathrm{pL}_{\text {mix }}\right)$. At $\bar{n}_{\text {mix }}=0.5$, in the formation curve, $\mathrm{pL}_{\text {mix }}=\log K_{M X Y}^{M X}(\operatorname{method} \mathrm{A})$. The values of $\log K_{M X Y}^{M X}$ were also evaluated by the graphical method (B), by plotting the graph of $\log$ $\left[\bar{n}_{\text {mix }} /\left(1-\bar{n}_{\text {mix }}\right)\right]$ against $\mathrm{pL}_{\text {mix }}$. The values of $\bar{n}_{\text {mix }}$ vary from $0.0-1.0$, thus confirm the formation of 1:1:1 mixed ligand complexes. The values obtained by method A and B are in agreement with each other, the average values of $\log K_{M X Y}^{M X}$ are included in Table 1.

Table 1. Metal-ligand stability constants of binary (M-Y), ternary (M-X-Y) systems and $\Delta$ $\log \mathrm{K}_{\mathrm{T}}$ values in $75: 25(\mathrm{v} / \mathrm{v})$ 1,4-dioxne-water medium at $27 \pm 0.5^{\circ} \mathrm{C}$ and $\mu=0.1 \mathrm{M}(\mathrm{KCl})$

\begin{tabular}{cccccc}
\hline \multirow{2}{*}{ System } & $\begin{array}{c}\text { Metal-ligand } \\
\text { stability constants / } \\
\Delta\end{array}$ & \multicolumn{4}{c}{ Metal(II) ions (M) } \\
\cline { 3 - 6 } & $\log \mathrm{K}_{\mathrm{T}}$ & $\mathrm{Mn}(\mathrm{II})$ & $\mathrm{Ni}(\mathrm{II})$ & $\mathrm{Cu}(\mathrm{II})$ & $\mathrm{Zn}(\mathrm{II})$ \\
\hline & $\log K_{M Y_{1}}^{M}$ & 3.59 & 3.68 & 6.63 & 3.25 \\
Binary (M-Y) & $\log K_{M Y_{2}}^{M Y}$ & 2.93 & 2.97 & 3.21 & 2.85 \\
& $\log \beta$ & 6.52 & 6.65 & 9.84 & 6.10 \\
Ternary (M-X-Y) & $\log K_{M X Y}^{M X}$ & 3.35 & 3.40 & 6.31 & 2.95 \\
$(\mathrm{M}-\mathrm{Y})$ and (M-X-Y) & $\Delta \log \mathrm{K}_{\mathrm{T}}$ & -0.24 & -0.28 & -0.32 & -0.30 \\
\hline
\end{tabular}

The values of $\log K_{M X Y}^{M X}$ are slightly lower than $\log K_{M Y_{1}}^{M}$ and higher than $\log K_{M Y_{2}}^{M Y}$, which is due to the fact that the tendency of the secondary ligand $(\mathrm{Y})$ to get bound with aquated metal ion $[\mathrm{M}(\mathrm{aq})]^{2+}$ is more than to combine with the metal ion already bound with primary ligand $(\mathrm{X})^{12}$.

The relative stability of the ternary complexes compared with corresponding binary complexes can be qualitatively expressed in many different ways. We have expressed the relative stabilities in terms of $\Delta \log \mathrm{K}_{\mathrm{T}}\left(\Delta \log \mathrm{K}_{\mathrm{T}}=\log K_{M X Y}^{M X}-\log K_{M Y_{1}}^{M}\right)$. The $\Delta \log \mathrm{K}_{\mathrm{T}}$ values for all the metal(II) ions in the present study (Table 1) is negative. This indicates that ternary 1:1:1 (M-X-Y) complexes are less stable than binary 1:1 (M-Y) complexes $^{13,14}$.

In the ternary system studied, the order of stability constants of mixed ligand complexes with respect to the metal ions was found to be $\mathrm{Cu}(\mathrm{II})>\mathrm{NI}$ (II) $>\mathrm{Mn}$ (II) $>\mathrm{Zn}$ (II); which is same as in the corresponding binary (M-Y) systems. This is in accordance with the IrvingWilliams series of stability constant ${ }^{15,16}$.

\section{Conclusion}

The value of $\log K_{M X Y}^{M X}$ are slightly lower than $\log K_{M Y_{1}}^{M}$ and higher than $\log K_{M Y_{2}}^{M Y}$, which is due to the fact that the tendency of the secondary ligand $(\mathrm{Y})$ to get bound with aquated metal ion $[\mathrm{M}(\mathrm{aq})]^{2+}$ is more than to combine with the metal ion already bound with primary ligand $(\mathrm{X})$. The relative stability $\left(\Delta \log \mathrm{K}_{\mathrm{T}}\right.$ ) values of the ternary complexes with corresponding binary complexes for all the metal(II) ions in the present study is negative indicating that ternary 1:1:1 (M-X-Y) complexes are less stable than binary 1:1 (M-Y) complexes. In the ternary system studied, the order of stability constants of mixed ligand complexes with respect to the metal ions was found to be $\mathrm{Cu}(\mathrm{II})>\mathrm{NI}(\mathrm{II})>\mathrm{Mn}(\mathrm{II})>\mathrm{Zn}$ (II); which is same as in the corresponding binary (M-Y) systems. 


\section{References}

1. Schiff H, Ann Chem Suppl., 1864, 3, 343.

2. Martell A E and Matekaitis R J, Can J Chem., 1982, 60.

3. Rukmani V, Prachi K and Mangaonkar K V, Asian J Chem., 2008, 20(2), 949-953.

4. Kiramany K, Prashanthi Y, Subhashini N J P and Shivraj, J Chem Pharm Res., 2010, 2(1), 375 .

5. Irving H M and Rossotti H S, J Chem Soc., 1953, 3397.

6. Irving H M and Rossotti H S, J Chem Soc., 1954, 2904.

7. Valecha S and Mangaonkar K, Asian J Chem., 2008, 20, 967.

8. Nair M S, Arasu P T, Pillai M S and Natarajan C, Talanta, 1993, 40, 1411.

9. Pessoa J C, Boas L F V and Gillard R D, Polyhedron, 1989, 8, 1173-1199.

10. Patel R N and Pandeya K B, Indian J Chem., 1990, 29(A), 602.

11. Vogel A I, Text Book of Quantitative Practical Inorganic Chemistry, ELBS, 1984.

12. Mapari A K and Mangaonkar K V, E- J Chem., 2011, 8(1), 123-126.

13. Satyanarayana S and Reddy K V, Indian J Chem., 1989, 28(A), 169.

14. Neelakantan M A and Nair M S, Iran J Chem Chem Eng., 2004, 23(1), 97-102.

15. Irving H and William R J P, J Chem Soc., 1953, 8, 3192.

16. Irving H and William R J P, Nature, 1948, 162, 746-747. 


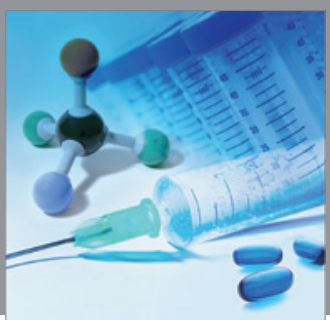

International Journal of

Medicinal Chemistry

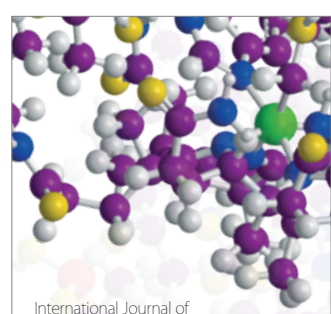

Carbohydrate Chemistry

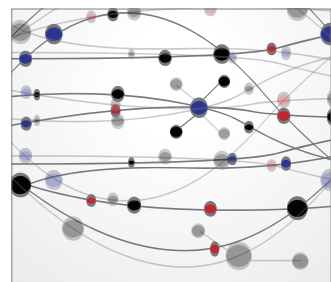

The Scientific World Journal
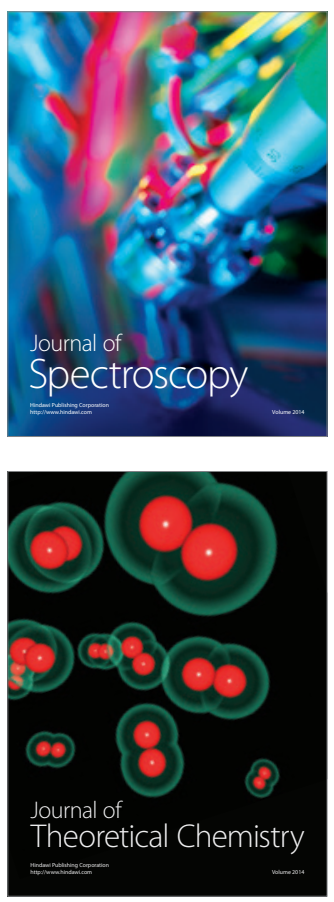
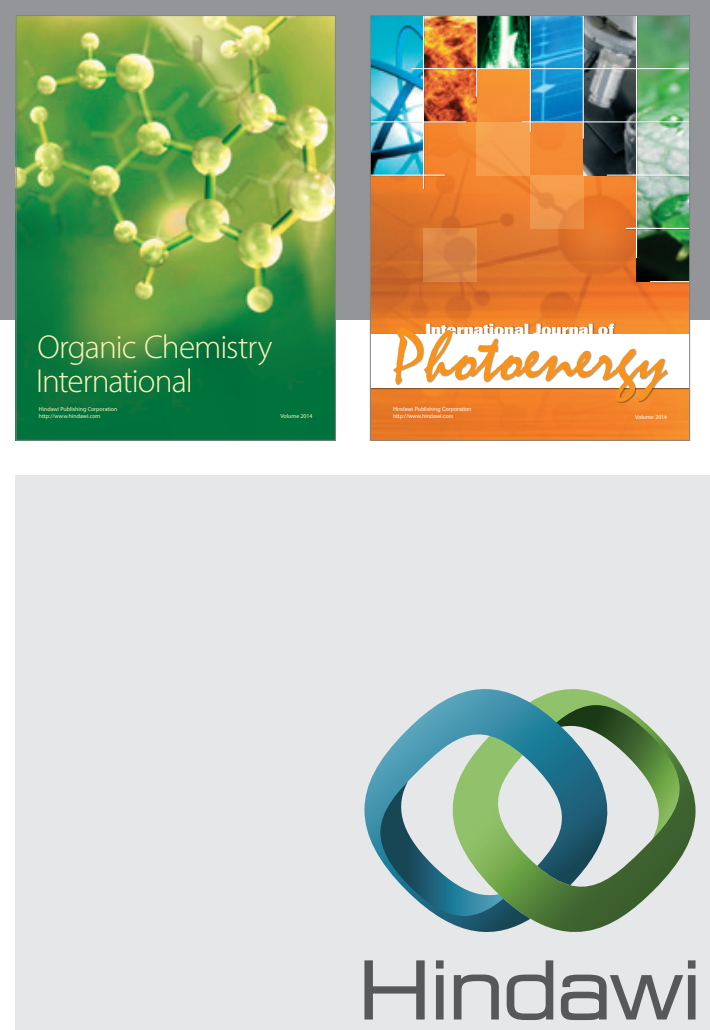

Submit your manuscripts at

http://www.hindawi.com
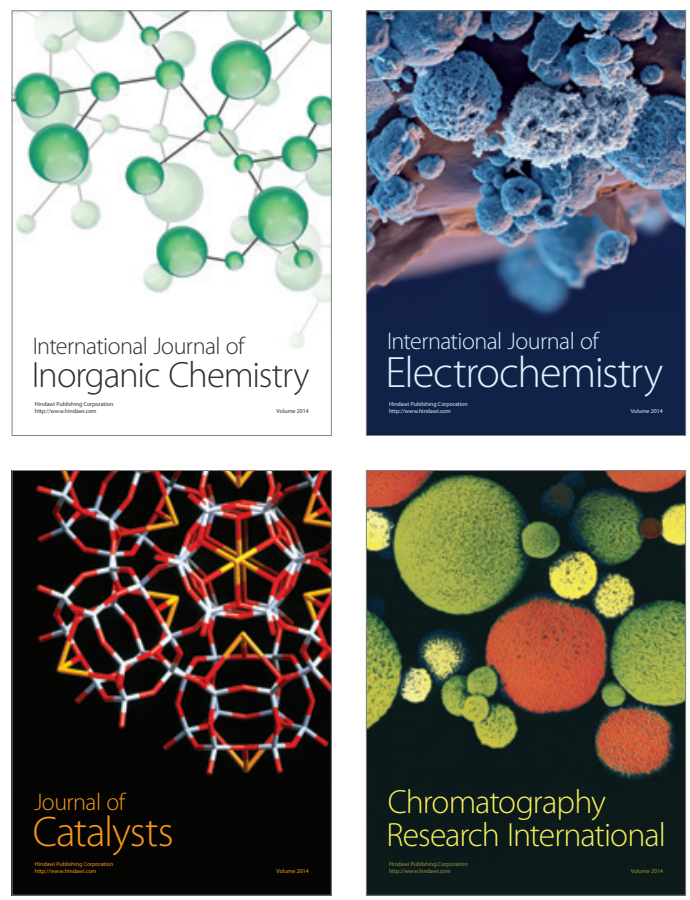
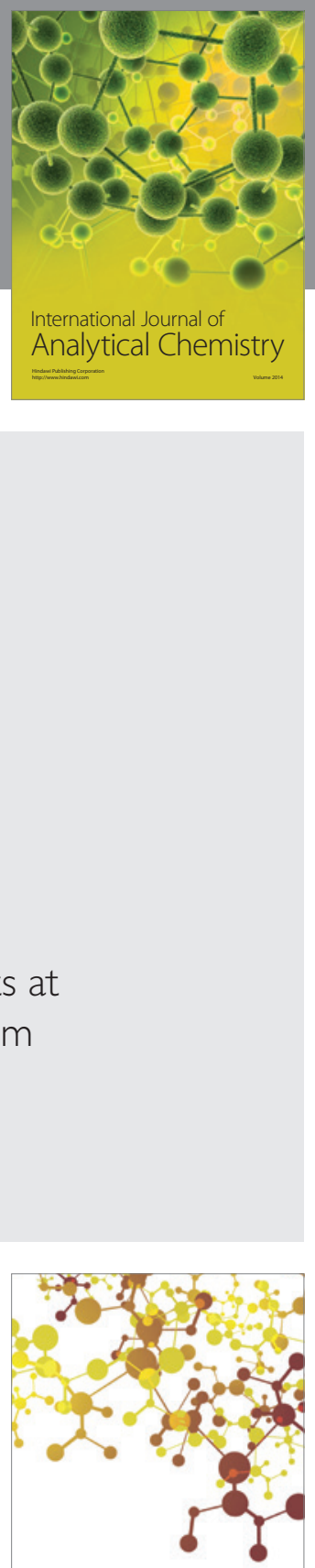

Journal of

Applied Chemistry
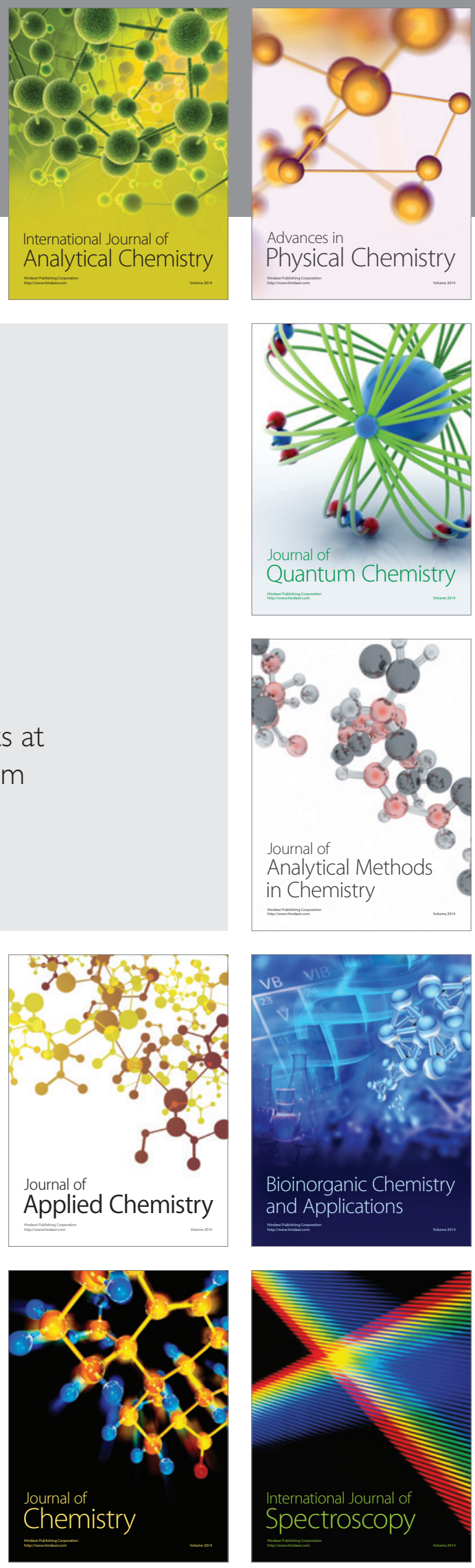